\title{
LITTER SIZE, OVARIAN CHARACTERISTICS, AND OOCYTE IN VITRO MATURATION AND FERTILIZATION OF RABBITS ADMINISTRATED WITH COENZYME Q10 AND L-CARNITINE
}

\author{
G.E. Younan ${ }^{1}$; H.A. El-Nagar' ${ }^{1}$ W.M. Wafa ${ }^{1}$; I.T. El-Ratel ${ }^{1}$ and A.E. Abdel-Khalek ${ }^{2}$ \\ ${ }^{1}$ Animal Production Research Institute, Agricultural Research Center, Dokki, Giza, Egypt. \\ ${ }^{2}$ Animal Production Department, Faculty of agriculture, Mansoura University, Egypt.
}

SUMMARY

$\mathrm{T}$ The objective of this study was to evaluate the effect of coenzyme Q10 (CoQ10) and L-carnitine (LC) administration on litter size, ovarian characteristics and in vitro production of rabbit embryos. This study was carried out at the International Livestock Management Training Center (ILMTC), belonging to the Animal Production Research Institute, Agricultural Research Center, Ministry of Agriculture. Total of 36 mature NZW rabbit does (5-6 months of age, 3-3.5 kg LBW as well as 6 NZW bucks (7.5-8 months of age and 3.5-4.0 kg LBW) were used in this study. Does were divided into 3 similar groups, $(\mathrm{n}=12)$. The 1 group was control (G1), while does in the 2 and 3 groups were given daily oral dose of $10 \mathrm{mg}$ CoQ10/kg LBW (G2) and $40 \mathrm{mg} \mathrm{LC} / \mathrm{kg} \mathrm{LBW}$ (G3) for 21 days prior to natural mating, respectively. Five does from each group were slaughtered post-mating as oocyte donors for studying the effect of treatments on ovarian characteristics and in vitro maturation and fertilization of oocytes. Immediately after slaughtering, ovaries were removed and oocytes were collected by slicing technique and evaluated, then only compactcumulus oocytes (COCs) were matured and fertilized in vitro. For the rest number of does in each group $(\mathrm{n}=7)$, pregnancy was handy diagnosed by palpation 10-12 days post-mating. Also, litter size and weight at birth up to weaning were recorded. The obtained results showed that, ovarian weight and number of follicles increased $(\mathrm{P}<0.05)$ in $\mathrm{G} 2$ and G3. Number of bleeding follicles and recovered oocytes increased $(\mathrm{P}<0.05)$ only in G2 as compared to G1, however, oocyte recovery rate was not affected by treatment. Frequency distribution of compact and partial denuded oocytes was higher $(\mathrm{P}<0.05)$, while that of expanded and denuded oocytes was lower in G2 and G3 as compared to G1. Percentage of oocytes with full expansion (maturation rate) was 80.3 and $79.3 \%$ vs. $73.8 \%$ and fertilization rate was 67.4 and $66.7 \%$ vs. $64.5 \%$ in G2 and $\mathrm{G} 3$ vs. $\mathrm{G}((\mathrm{P} \geq 0.05)$. Percentage of embryos at morula stage was higher $(\mathrm{P}<0.05)$ in $\mathrm{G} 2$ and $\mathrm{G} 3$ than in $\mathrm{G} 1$ (30.3 and $3.1 \%$ vs. $20 \%$ ), respectively. Percentage of embryos at blastocyst stage was 21.2 and $21.4 \%$ vs. $15 \%$ in G2 and G3 vs. G1, respectively. Litter size of rabbit does was higher $(\mathrm{P}<0.05)$ in G2 and G3 than in G1 at birth (7.29 and 6.71 vs. 5.43/doe), at 21 days of age (6.71 and 5.86 vs. $4.43 /$ doe) and at weaning (6.43 and 5.43 vs. $4.14 /$ doe). Mortality rate of kits at birth or weaning was not affected by treatment. Average kit weight at birth was higher $(\mathrm{P}<0.05)$ in $\mathrm{G} 2$ and $\mathrm{G} 1$. However, average kit weight at weaning, average litter weight from birth up to weaning and average litter daily gain from birth up to weaning were higher $(\mathrm{P}<0.05)$ in $\mathrm{G} 2$ and $\mathrm{G} 3$ than in G1.

In conclusion, treatment of rabbit does 21 days prior to insemination with CoQ10 at a level of $10 \mathrm{mg} / \mathrm{kg}$ LBW or L-carnitine at level $40 \mathrm{mg} / \mathrm{kg} \mathrm{LBW}$ as daily oral dose is recommended to improve in vitro embryo production and also to increase litter characteristics (size and weight from birth up to weaning) of New Zealand White rabbit does.

Keywords: Rabbit, coenzyme Q10, L-carnitine, oocyte, in vitro maturation and fertilization.

\section{INTRODUCTION}

Mammalian ovaries contain a large number of oocytes enclosed in primordial follicles. Ovarian cyclic activity induces some of these follicles to initiate growth towards ovulation. However, in growing follicles, only subsets of oocytes are capable to support maturation, fertilization and early embryo development (Mermillod et al., 2008). Metabolism and adenosine tri-phosphate (ATP) levels within the oocyte and adjacent cumulus cells are associated with oocyte quality and optimal development of a healthy embryo. Mitochondria play a key role in the physiology of eukaryotic cells during all stage of life including the pre-implantation period and their main function is to provide cells with ATP through oxidative phosphorylation (Cummins, 2004; Smith et al., 2005). Mitochondrial dysfunction may lead to incomplete detoxification of the free radicals, which may lead to oxidative damage to macromolecules such as lipids, proteins, and DNA (Abdelrazik et al., 2009). In vivo oocytes rely on mitochondrial 
oxidative phosphorylation for energy, a process which is subsequently accompanied by reactive oxygen species (ROS) generation (du Plessis et al., 2008). Thus, poor oocyte quality would lead to compromised embryo development. In the oocyte, ROS levels when present in excess, can disrupt the oocyte cytoskeleton (du Plessis et al., 2008).

The cytoplasm of ruminant oocyte and pre-implantation embryos are rich in lipid droplets, which, in compact cumulus oocytes (COCs) are associated with the endoplasmic reticulum and mitochondria and are degraded to some extent during maturation (Kruip et al., 1983; McEvoy et al., 2000). The B-oxidation pathway that metabolizes lipids/fatty acids within the mitochondria to generate cellular ATP has an essential role in determining oocyte quality and its ability to support embryo development (Van Blerkom et al., 1995; Stojkovic et al., 2001; Fergusson and Leese, 2006).

In the animal body, carnitine can be synthesized from protein-bound lysine and methionine in two forms (L- and D-carnitine) and L-carnitine (LC) is biologically the active form (Vaz and Wanders, 2002). It is vitamin-like amino-acid as a polar natural compound (Groff and Gropper, 2000), playing an important role in the cellular detoxification (Arrigoni-Martelli and Caso, 2001) and in lipid metabolism by carrying long-chain fatty acids to the mitochondria for $\beta$-oxidation to produce ATP required for cell function (Hoppel, 2003). It is also important as antioxidant for protection of the cell membranes against oxidative damages (Kalaiselvi and Panneerselvam, 1998).

Recently, Manzano et al. (2015) showed that nuclear maturation and cleavage rate of COCs were not influenced by the presence of LC during the initial maturation period, but LC supplementation was effective at supporting blastocyst formation and improving its quality as evidenced by having a higher total cell count. In this respect, You et al. (2012) mentioned that LC plays an important role in the lipids/fatty acid metabolism as an endogenous energy source for the oocytes and embryos. There is multiple reports demonstrating that LC treatment in vitro can improve embryo development, however little is known about whether circulating carnitine or in vivo supplementation with LC can improve embryo quality (Eder, 2009). The unique dual effects of LC in terms of reducing cellular lipid content and providing antioxidative protection make it a novel candidate reagent for the non-invasive improvement of cryo-tolerance and developmental competence in embryos of farm animals (Takahashi et al., 2013). There has been very little investigation of whether LC supplementations in vivo can impudence oocyte quality or embryo growth, however, Miyamoto et al. (2010) reported that LC in the drinking water (5 $\mathrm{mg} / \mathrm{ml}$ ) improved ovulation rates in the 'aged' ovaries, normalized the alterations in oocyte mitochondria and markers of oxidative stress and improved blastocyst development.

Coenzyme Q10 (CoQ10) is a fat soluble vitamin-like substance present in every cell of the body and serves as a coenzyme for several of the key enzymatic steps of in the production of energy within the cell (Kapoor and Kapoor, 2013). CoQ10 plays a key role in the mitochondrial electron transport chain, and it is a critical coenzyme in the synthesis of ATP (Abdulhasan et al., 2015). Also, CoQ10 is an antioxidant that has great importance against free radicals (Bentinger et al., 2007), protects the stability of the cell membrane, DNA from free radicals induced oxidative damage and helps recycling of vitamin $\mathrm{E}$ and maintain healthy energy levels (El-Tohamy et al., 2012). Moreover, dietary supplementation with CoQ10 may increase mitochondrial activity within the oocyte and developing embryo (Bentov et al., 2010). Since tissue levels of CoQ10 decrease with age, supplementation of this agent may improve mitochondrial function in the ovary and may improve oocyte and embryo quality, especially in women of advanced reproductive age (Scott, 2013).

Therefore, aim of the present work was to study the effect of treatment of rabbit does for $21 \mathrm{~d}$ premating with coenzyme Q10 (10 mg/kg LBW) and L-Carnitine (40 mg/kg LBW) on follicular number, and recovery rate, in vitro maturation, fertilization and development of follicular oocytes.

\section{MATERIALS AND METHODS}

This study was carried out at the International Livestock Management Training Center (ILMTC), belonging to the Animal Production Research Institute, Agricultural Research Center, Ministry of Agriculture.

\section{Animals:}

Total of 36 New Zealand white (NZW) mature rabbit does (5-6 mo of age and 3.0-3.5 kg live body weight) as embryo donors as well as $6 \mathrm{NZW}$ bucks aging 7.5-8.0 mo and weighing 3.5-4.0 kg for natural mating were used in this study during the experimental period.

\section{Experimental groups:}


Rabbit does were divided randomly into 3 groups, $(n=12)$ per group. The 1st group (G1) was considered as a control group without treatment (G1), while does in the 2nd and 3rd groups were given 10 $\mathrm{mg}$ Coenzyme Q10 (CoQ10)/kg LBW and $40 \mathrm{mg} \mathrm{L-Carnitine} \mathrm{(LC)/kg} \mathrm{LBW} \mathrm{as} \mathrm{daily} \mathrm{oral} \mathrm{doses} \mathrm{for} 21$ days as a treatment period prior to mating. Natural mating was carried with fertile bucks and pregnancy was handy diagnosed by palpation ten to twelve days post mating to detect the pregnancy.

\section{Experimental procedures:}

Post-mating, five rabbit does were taken from each group, slaughtered, and immediately after slaughtering ovaries of each doe were removed, washed by distilled water and dried by cleaning paper. Ovaries were excised, submerged in a flacon plastic tissue culture dishes $(60 \times 15 \mathrm{~mm})$ containing saline solution at $38.5^{\circ} \mathrm{C}$ for in vitro study. On the other hand, the remainder number of rabbit does in each group $(n=7)$ were kept under the same feeding and managerial conditions up to kindling for in vivo study.

\section{In vitro study:}

\section{Oocyte recovery:}

Follicular oocytes were collected using slicing technique into tissue culture dishes containing $4 \mathrm{ml}$ of phosphate buffer saline (PBS) as a harvesting medium, supplemented with $4 \mathrm{mg}$ bovine serum albumin (BSA)/ml, $100 \mathrm{IU}$ sodium penicillin G/ml, (Misr Co. for Pharm., Egypt) and $100 \mu \mathrm{g}$ streptomycin $/ \mathrm{ml}$. Oocytes were examined under stereomicroscopy and classified according to their compaction, number of cumulus cell layers and homogeneity of ooplasm as described by Ravindranatha et al. (2003) to compact cumulus oocytes (COCs), expanded cumulus oocytes, partial denuded cumulus oocytes and denuded cumulus oocytes. Oocytes were recovered from only compact-cumulus oocytes (COCs) were used in this study.

\section{In vitro maturation (IVM):}

Maturation in vitro rate of oocytes was evaluated using tissue culture medium (TCM-199) containing $10 \%$ (v./v.) from doe rabbit serum (DRS) supplemented with $100 \mathrm{IU}$ sodium penicillin G and $100 \mu \mathrm{g}$ streptomycin per $\mathrm{ml}$. The $\mathrm{pH}$ value of the medium was adjusted to 7.2-7.4 and osmolarity of 280-300 $\mathrm{mOsmol} / \mathrm{kg}$. The medium was filtered by $0.22-\mu \mathrm{m}$ millipore filter (Milieux GV, milpore, Cooperation Bedford MOA). Each of $500 \mu \mathrm{l}$ from prepared maturation medium was placed into four well dishes and covered by sterile mineral oil. Before placing the oocytes in culture dishes, the medium was incubated in $\mathrm{CO} 2$ incubator $\left(5 \% \mathrm{CO} 2\right.$, at $38{ }^{\circ} \mathrm{C}$ with saturated humidity) for at least 60 minutes to attain equilibrium between the temperature and gases. Compact cumulus oocytes (COCs) were washed three times with maturation medium, then cultured in the medium and incubated under the same conditions for $20 \mathrm{~h}$.

The morphology of matured oocytes was evaluated for cumulus cell expansion as full, partial and no expanded oocytes. In vitro maturation rate was expressed in term of percentage of oocytes with full expansion.

\section{Sperm capacitation and in vitro fertilization:}

Semen was collected from rabbit bucks and the jelly mass of each ejaculate was discarded and net volume of 10 ejaculates was used for sperm capacitation. PBS supplemented with 100 IU sodium penicillin $\mathrm{g}$ and $100 \mu \mathrm{g}$ streptomycin and $4 \mathrm{mg} / \mathrm{ml} \mathrm{BSA}$ was used. Medium was adjusted to $\mathrm{pH}$ 7.2-7.4 and osmolarity of $280-300 \mathrm{mOsmol} / \mathrm{kg}$ and filtered by $0.22-\mu \mathrm{m}$ millipore filter. Sperm capacitation was performed by $35 \mu \mathrm{g} / \mathrm{ml}$ of heparin. Fertilization droplets were prepared by pipetting $50 \mu 1$ of fertilization medium under sterile liquid paraffin oil and incubated at $38^{\circ} \mathrm{C}$ for $2 \mathrm{~h}$ in $5 \% \mathrm{CO} 2$ in air and high humidity. About $5 \mu \mathrm{l}$ of washing media was added to each droplet with 7-10 oocytes followed by adding $2 \mu \mathrm{l}$ of prepared semen and then incubated together at $38^{\circ} \mathrm{C}$ for $24 \mathrm{~h}$ in $5 \% \mathrm{CO} 2$ in air. Fertilizing rate after $24 \mathrm{~h}$ and developmental competence of embryos at different embryonic stages after $72 \mathrm{~h}$ were investigated.

\section{Criteria of fertilized oocytes:}

After fertilization, oocytes were examined using inverted microscope into normal fertilized oocytes containing both male and female pronucli in their cytoplasm plus second polar body, unfertilized oocytes with unknown criteria and degenerated oocytes exhibiting fragment or scattered chromatin complement in their cytoplasm. Also, the stage of cleavage was classified into embryos at 2-4 cell, 8-16 cell, morula and blastocyst stages.

\section{In vivo study:}

In this study, the rest number of does in each group (seven does) was allowed to continue to pregnancy and kindling. After the positive mating the nest boxer were supplied with sawdust in the 25 
days of pregnancy to provide a comfortable and warm nest for bunnies. Litter size at birth, $21 \mathrm{~d}$ of age and weaning (28 d of age), mortality rate at birth and weaning as well as litter weight at birth, 1st, 2nd, 3rd and 4th wk of age were determined.

\section{Statistical analysis:}

Data were analyzed by analysis of variance using computer program of SAS (1998). The significant differences among group means were performed using Duncan Range Test (Duncan, 1955).

\section{RESULTS AND DISCUSSION}

\section{In vitro study:}

\section{Follicular number and oocyte recovery:}

Data in Table (1) revealed that Ovarian weight and number of follicles increased $(\mathrm{P}<0.05)$ in $\mathrm{G} 2$ and G3. Number of bleeding follicles and recovered oocytes increased $(\mathrm{P}<0.05)$ only in $\mathrm{G} 2$ as compared to G1. However, oocyte recovery rate was not affected by treatment.

It is of interest to note that increasing ovarian weight of does in both treatment groups was associated with increasing number of bleeding and large follicles in G2 and only increasing number of large follicles in G3. In addition, number of recovered oocytes increased significantly $(\mathrm{P}<0.05)$ by CoQ10 treatment and insignificantly by LC treatment. No information are available on the effect of LC or CoQ10 on the ovarian activity of animals, but in a single study of El-Shahat and Abo-Elmaaty (2010) in ewes, dietary supplementation of $250 \mathrm{ppm}$ LC for 56 days increased the number of medium and large ovarian follicles. Also, LC supplementation in the drinking water $(5 \mathrm{mg} / \mathrm{ml})$ improved ovulation rates in the 'aged' ovaries (Miyamoto et al., 2010). The addition of LC to cultured mouse follicles for 12 days, from the pre-antral to large-antral stage, increased $\beta$-oxidation (Dunning et al., 2011).

Table (1). Ovarian characteristics and ovulatory response of rabbit does as affected by CoQ10 and L-Carnitine (LC) treatments.

\begin{tabular}{lccc}
\hline \multirow{2}{*}{ Characteristics } & \multicolumn{3}{c}{ Experimental group } \\
\cline { 2 - 4 } & G1 (control) & G2 (CoQ10) & G3 (LC) \\
\hline Ovarian weight, $\mathrm{g}$ & $0.37 \pm 0.002 \mathrm{~b}$ & $0.48 \pm 0.042 \mathrm{a}$ & $0.51 \pm 0.024 \mathrm{a}$ \\
Number of bleeding follicles, $\mathrm{n}$ & $1.00 \pm 0.5 \mathrm{~b}$ & $2.40 \pm 0.2 \mathrm{a}$ & $1.60 \pm 0.2 \mathrm{ab}$ \\
Number of visible follicles, $\mathrm{n}$ & $20.00 \pm 0.5 \mathrm{c}$ & $24.40 \pm 0.4 \mathrm{a}$ & $21.80 \pm 0.5 \mathrm{~b}$ \\
Number of recovered oocytes, $\mathrm{n}$ & $16.00 \pm 1.0 \mathrm{~b}$ & $19.20 \pm 0.4 \mathrm{a}$ & $17.40 \pm 0.2 \mathrm{ab}$ \\
Oocyte recovery rate, $\%$ & $84.0 \pm 1.0$ & $87.3 \pm 0.7$ & $87.9 \pm 1.2$ \\
\hline
\end{tabular}

$a, b$ and $c:$ Means within the same row with different superscripts are significantly different at $P<0.05$.

\section{Categories of recovered follicular oocytes:}

Data in Table (3) clearly revealed that frequency distribution of compact and partial denuded oocytes was significantly $(\mathrm{P}<0.05)$ higher, while that of expanded and denuded oocytes was significantly $(\mathrm{P}<0.05)$ lower in G2 and G3 as compared to G1. This means that both treatments either CoQ10 or LC had impact on quality of recovered oocytes in term of frequency distribution of compact oocytes as compared to controls, being insignificantly better with CoQ10 than LC.

Table (2). Frequency distribution of rabbit oocyte categories as affected by CoQ10 and L-Carnitine treatment.

\begin{tabular}{lccc}
\hline \multirow{2}{*}{ Oocyte category $(\%)$} & \multicolumn{3}{c}{ Experimental group } \\
\cline { 2 - 4 } & G1 (control & G2 (CoQ10) & G3 (LC) \\
\hline Compact & $52.4 \pm 0.6 \mathrm{~b}$ & $63.7 \pm 2.2 \mathrm{a}$ & $60.9 \pm 1.1 \mathrm{a}$ \\
Expanded & $6.4 \pm 0.51 \mathrm{a}$ & $5.2 \pm 0.13 \mathrm{~b}$ & $5.8 \pm 0.12 \mathrm{ab}$ \\
Partial denuded & $11.1 \pm 0.7 \mathrm{c}$ & $16.5 \pm 1.7 \mathrm{~b}$ & $21.8 \pm 1.2 \mathrm{a}$ \\
Denuded & $30.1 \pm 0.7 \mathrm{a}$ & $14.6 \pm 0.8 \mathrm{~b}$ & $11.5 \pm 0.2 \mathrm{c}$ \\
\hline
\end{tabular}

$a, b$ and $c$ : Means within the same row with different superscripts are significantly different at $P<0.05$.

Oocyte quality is important for fertilization and development into viable offspring. Quality compromised oocytes are correlated with infertility, developmental disorders, reduced blastocyst cell number and embryo loss, but the 
mechanisms underlying these effects are not well understood. Oocyte quality is achieved during the maturation process. Maturation defects can have several causes and have been associated with mitochondrial dysfunction (Schatten and Sun, 2011a, b) due to insufficient ATP, calcium homeostasis, hormonal effects, and several others. The B-oxidation pathway that metabolizes lipids/fatty acids within the mitochondria to generate cellular ATP has an essential role in determining oocyte quality and its ability to support embryo development (Fergusson and Leese, 2006).

In accordance with the present study Miyamoto et al. (2010) has shown that LC can improve oocyte quality in mice by normalizing the alterations in oocyte mitochondria and markers of oxidative stress. In the same line, dietary supplementation with CoQ10 have also been considered to improve mitochondria functions in quality-compromised oocytes (Bentov et al., 2010) and may increase mitochondrial activity and function within the oocyte (Bentov et al., 2010; Scott, 2013), especially with decreasing levels of CoQ10 with age in women (Scott, 2013). CoQ10 is a coenzyme that aids in the transport of electrons along the mitochondrial respiratory chain.

\section{Maturation, fertilization and embryonic stages of follicular oocytes:}

Data in Table (3) showed that percentage of oocytes with full expansion (Maturation rate) was 80.3 and $79.3 \%$ vs. $73.8 \%$ and fertilization rate was 67.4 and $66.7 \%$ vs. $64.5 \%$ in G2 and G3 vs. G1 without significant differences among groups $(\mathrm{P} \geq 0.05)$. However, percentage of embryos at morula stage was significantly $(\mathrm{P}<0.05)$ higher in G2 and G3 than in G1 (30.3 and 3.1\% vs. 20\%), respectively. Yet, the differences in percentage of embryos at blastocyst stage among groups were not significant, being 21.2 and $21.4 \%$ vs. $15 \%$ in G2 and G3 vs. G1), respectively. Such findings may indicate positive effect of both treatments only on morula production rate.

Table (3). Oocyte expansion (maturation rate), fertilization rate and embryonic stages of oocytes in vitro matured as affected by CoQ10 and L-Carnitine treatments.

\begin{tabular}{|c|c|c|c|c|c|c|c|c|c|c|c|c|c|}
\hline \multirow{3}{*}{$\begin{array}{l}\text { Experimental } \\
\text { group }\end{array}$} & \multirow{3}{*}{$\mathrm{N}$} & \multirow{2}{*}{\multicolumn{2}{|c|}{$\begin{array}{c}\text { Oocyte } \\
\text { expansion }\end{array}$}} & \multirow{2}{*}{\multicolumn{2}{|c|}{$\begin{array}{l}\text { Fertilized } \\
\text { oocytes }\end{array}$}} & \multicolumn{8}{|c|}{ Embryonic stage } \\
\hline & & & & & & \multicolumn{2}{|c|}{ 2-4cell } & \multicolumn{2}{|c|}{$8-16$ cell } & \multicolumn{2}{|c|}{ Morula } & \multicolumn{2}{|c|}{ Blastocyst } \\
\hline & & $\mathrm{n}$ & $\%$ & $\mathrm{n}$ & $\%$ & $\mathrm{n}$ & $\%$ & $\mathrm{n}$ & $\%$ & $\mathrm{n}$ & $\%$ & $\mathrm{n}$ & $\%$ \\
\hline G1 (control) & 42 & 31 & 73.8 & 20 & 64.5 & 6 & 30.0 & 7 & $35.0 \mathrm{a}$ & 4 & $20.0 \mathrm{~b}$ & 3 & 15.0 \\
\hline G2 (CoQ10) & 61 & 49 & 80.3 & 33 & 67.4 & 7 & 21.2 & 9 & $27.3 \mathrm{ab}$ & 10 & $30.3 a$ & 7 & 21.2 \\
\hline G3 (LC) & 53 & 42 & 79.3 & 28 & 66.7 & 6 & 21.4 & 7 & $25.0 \mathrm{~b}$ & 9 & $32.1 \mathrm{a}$ & 6 & 21.4 \\
\hline
\end{tabular}

$a$ and $b$ : Means within the same column with different superscripts are significantly different at $P<0.05$.

N: Total number of oocytes.

Mitochondria are critically important for oocyte maturation and they are reliable indicators for oocyte quality achieved during the maturation process (Schatten et al., 2014). The number of mitochondria varies in different species but in most mammalian species mitochondria are closely located around the MII spindle (Katayama et al., 2006). During oocyte maturation, the oocyte grows and undergoes remodeling on cellular and molecular levels. This remodeling requires ATP likely supplied by mitochondria; thereby allowing timely and accurate cytoplasmic and nuclear maturation (Sirard et al., 2006). Mitochondria supplied ATP is also important for protein phosphorylation and dephosphorylation which are among the regulatory events that play key roles in oocyte maturation, and include centrosome and microtubule dynamics for the formation of the meiotic spindles during meiosis I (MI) and II (MII) (Ai et al., 2009; Swain and Pool, 2008; Gosden and Lee, 2010; Schatten and Sun, 2011a,b). In the mouse oxidation is significantly up-regulated during both in vivo and in vitro oocyte maturation (Dunning et al., 2010).

LC is an enhancer of lipid metabolism in animal cells including oocytes; it has a role in the transport of fatty acids from the cytosol to the mitochondria to fuel beta-oxidation (Kerner and Hoppel, 2000). Supplementation of culture medium with LC reduced lipid content in bovine oocytes (Chankitisakul et al., 2013). The observed tendency of in vitro maturation in term of full expanded oocytes when recovered from rabbit does treated with LC is in agreement with the results of You et al. (2012), who found that immature mammalian COCs matured with LC had improved glutathione level during maturation, indicating that its influence is more prominent on the cytoplasmic maturation rather than nuclear maturation. LC improved the meiotic competence of mammalian oocytes by holding back the apoptosis of granulosa cells and enhancing its mitochondrial activity (Hashimoto, 2009; Somfai et al., 2011).

The current study indicated significant improvement in fertilization in vitro and developmental competence of embryos to reach blastocyst stage due to treatment of rabbit does with CoQ10 or LC. In this respect, Manzano et al. (2015) found that LC supplementation was effective at supporting blastocyst formation and improving its quality as evidenced by having a higher total cell count. Addition of LC to culture medium enhanced lipid metabolism and mitochondrial activity and decreased ROS levels, as well 
as improves MII and cleavage rates (Somfai et al., 2011), although the treatment does not impact blastocyst formation.

Inhibition of oxidation compromises meiotic resumption (Downs et al., 2009) and impairs embryonic development formation following fertilization (Dunning et al., 2010), suggesting that lipid metabolism plays essential roles in both nuclear and cytoplasmic maturation in the mouse. Furthermore, enhancing oxidation by supplement LC to the culture medium during in vitro follicle culture and in vitro maturation significantly improves mouse oocyte developmental competence (Dunning et al., 2010, 2011). In addition, Dunning and Robker (2012) demonstrated that LC to in vitro oocyte maturation and embryo growth media improves embryo outcomes, most likely by supplying the oocyte and embryo with an essential co-factor required to utilize fatty acids. Thus in vitro systems must be optimized to include adequate carnitine, in order to mimic in vivo physiological levels. In vivo, circulating carnitine levels are normally regulated within a narrow range and thus dietary carnitine supplementation may only affect tissue levels when carnitine levels are systemically dysregulated. Dunning et al. (2011) found that oocytes isolated from the follicles treated with LC had greater rates of maturity (metaphase II/MII), higher fertilization rates and improved blastocyst development. Also, Manzano et al. (2015) reported that LC supplementation was effective at supporting blastocyst formation and improving its quality as evidenced by having a higher total cell count.

Regard to the beneficial effects of CoQ10, Mirit Gendelman and Zvi Roth (2012) found that CoQ10 increased the expression of genes associated with the mitochondrial electron transport chain, and improved developmental competence of oocytes. Also, Kishi et al. (1993) found that incorporation of CoQ10 into the oocytes enhanced the proportion of embryos that developed to the blastocyst stage.

In vivo study:

\section{Litter size of does and mortality rate of bunnies:}

Data presented in Table (4) show that litter size of rabbit does was significantly $(\mathrm{P}<0.05)$ higher in $\mathrm{G} 2$ and G3 than in G1 at birth (7.29 and 6.71 vs. 5.43/doe), at 21 days of age (6.71 and 5.86 vs. 4.43/doe) and at weaning (6.43 and 5.43 vs. 4.14/doe), being significantly $(\mathrm{P}<0.05)$ higher in $\mathrm{G} 2$ than in G3 at $21 \mathrm{~d}$ and weaning age. Mortality rate of bunnies at birth or weaning was not affected by treatment, being insignificantly the lowest in G2, followed by G3 and the highest in G1. These results indicated beneficial effect of treatment of rabbit does with CoQ10 and LC on their litter size and mortality rate of their bunnies.

Table (4). Litter size of rabbit does and mortality rate of their bunnies as affected by CoQ10 and LCarnitine treatments.

\begin{tabular}{lcccc}
\hline \multirow{2}{*}{ Item } & \multicolumn{3}{c}{ Experimental group } & \multirow{2}{*}{ SEM } \\
\cline { 2 - 4 } & G1(Control) & G2 (CoQ10) & G3 (LC) & \\
\hline Litter size/doe: & $5.43 \mathrm{~b}$ & $7.29 \mathrm{a}$ & $6.71 \mathrm{a}$ & 0.286 \\
At birth (alive) & $4.43 \mathrm{c}$ & $6.71 \mathrm{a}$ & $5.86 \mathrm{~b}$ & 0.261 \\
At 21 days of age & $4.14 \mathrm{c}$ & $6.43 \mathrm{a}$ & $5.43 \mathrm{~b}$ & 0.297 \\
At weaning (28 days of age) & & & & \\
Mortality rate (\%): & 17.14 & 7.40 & 12.42 & 3.787 \\
At birth & 22.38 & 11.57 & 19.56 & 4.514 \\
At weaning & & & \\
\hline
\end{tabular}

$a$ and $b$ : Means within the same row with different superscripts are significantly different at $P<0.05$.

\section{Litter weight of bunnies:}

Results shown in Table (5) revealed that average bunny weight at birth was significantly $(\mathrm{P}<0.05)$ higher in G2 than in G1 and G3. However, average bunny weight at weaning, average litter weight from birth up to weaning and average litter daily gain from birth up to weaning were significantly $(\mathrm{P}<0.05)$ higher in $\mathrm{G} 2$ and $\mathrm{G} 3$ than in $\mathrm{G} 1$, being significantly $(\mathrm{P}<0.05)$ higher in $\mathrm{G} 2$ than in $\mathrm{G} 3$. This means that both treatments improved litter size and litter weight of does with further superiority of those treated with CoQ10.

In accordance with improving litter size of rabbit does in both treatment groups, LC was reported to play an important role in improvement of reproduction of buffalo cows (Noseir, 2003) and rams (Noseir and El-Amrawi, 2001). Also, LC has beneficial effects in both productive and reproductive performance of monogastric species including sows (Freemaut et al., 1993; Eder et al. (2003), mares (Iben and Leibertseder, 1994) and poultry (Leibertseder and Iben, 1994). In this respect, dietary LC fed during gestation and lactation increased the number of pigs born live (Musser et al., 1999) and number of pigs 
weaned (Eder et al., 2001). Since the amount of LC synthesized endogenously does not cover the requirement for maximum sow performance during pregnancy and lactation, dietary LC either increases the ovulation rate or reduces embryonic mortality in sows Eder et al. (2003).

An adequate supplementation of LC in animal nutrition enables to overcome an energy bottleneck with minimal performance losses improves energy, fatty and amino acid utilization and decreases nitrogen excretion (Baumgartner and Jacobs, 1999).

Table (5). Litter weight and litter daily gain of rabbit does and mortality rate of their bunnies as affected by CoQ10 and L-Carnitine treatments.

\begin{tabular}{|c|c|c|c|c|}
\hline \multirow{2}{*}{ Item } & \multicolumn{3}{|c|}{ Experimental group } & \multirow{2}{*}{ SEM } \\
\hline & G1 (Control) & G2 (CoQ10) & G3 (LC) & \\
\hline \multicolumn{5}{|l|}{ Average kit weight $(\mathrm{g})$ : } \\
\hline At birth & $52.29 \mathrm{~b}$ & $57.19 \mathrm{a}$ & $52.65 b$ & 1.519 \\
\hline At weaning & $341.1 b$ & $443.2 \mathrm{a}$ & $429.3 \mathrm{a}$ & 16.03 \\
\hline \multicolumn{5}{|l|}{ Average litter weight $(\mathrm{g})$ : } \\
\hline At birth & $282.9 c$ & $416.4 \mathrm{a}$ & $353.6 b$ & 16.83 \\
\hline At one wk of age & $554.3 \mathrm{~b}$ & $903.6 \mathrm{a}$ & $763.6 \mathrm{a}$ & 54.81 \\
\hline At two wk of age & $771.4 \mathrm{c}$ & $1382.1 \mathrm{a}$ & $1137.1 b$ & 54.15 \\
\hline At three wk of age & $997.1 \mathrm{c}$ & $1800.0 \mathrm{a}$ & $1473.6 b$ & 62.41 \\
\hline At weaning (4 wk of age) & $1402.9 \mathrm{c}$ & $2837.1 \mathrm{a}$ & $2277.1 b$ & 116.5 \\
\hline \multicolumn{5}{|c|}{ Average litter daily gain (g/litter/d): } \\
\hline Birth $\sim 1$ st wk & $38.78 b$ & $69.59 a$ & $58.57 \mathrm{a}$ & 6.726 \\
\hline $1 \mathrm{st} \sim 2 \mathrm{nd}$ wk & $31.02 \mathrm{c}$ & $68.37 \mathrm{a}$ & $53.37 \mathrm{~b}$ & 4.333 \\
\hline 2nd $\sim 3 \mathrm{rd} \mathrm{wk}$ & $32.25 \mathrm{c}$ & $59.69 a$ & $48.06 \mathrm{~b}$ & 2.362 \\
\hline 3 rd $\sim 4$ th wk & $57.96 \mathrm{c}$ & $148.2 \mathrm{a}$ & $114.8 \mathrm{~b}$ & 9.709 \\
\hline
\end{tabular}

$a$ and $b$ : Means within the same row with different superscripts are significantly different at $P<0.05$.

Also, LC protects cell membrane and DNA against damage (Ye et al., 2010) by reducing the accumulation of ROS, enhancing the activity of numerous antioxidant enzymes, eg., superoxide dismutase, catalase and glutathione peroxidase (Rizzo et al., 2010) and has a pivotal role in mitochondrial oxidation of long-chain fatty acids which increase energy supply to the cell (Zhou et al ., 2007). Moreover, Musser et al. (1999) showed that dietary LC increased the concentrations of insulin and IGF-1 in the blood of sows during pregnancy. Other researchers have observed effects of LC supplementation on IGF system by increasing plasma IGF-I and IGF-II (Doberenz et al., 2005) when LC is supplemented in the diet.

On the other hand, dietary supplementation with CoQ10 may also improve embryo quality (Scott, 2013). CoQ10 increased the ATP content in expanded blastocysts (Stojkovic et al., 1999), stimulated ATP formation in myocardial cells of mouse fetuses (Kishi et al., 1993). Also, dietary supplementation with CoQ10 may increase mitochondrial activity and function within the developing embryo (Bentov et al., 2010). Subsequently, a superior rate of early bovine embryo cleavage, blastocyst formation, percentage of expanding blastocysts, and a larger inner cell mass as affected by CoQ10 (Marriage et al., 2004). In addition, CoQ10 is antioxidant that has great importance against free radicals (Bentinger et al., 2007).

In conclusion, treatment of rabbit does 21 days prior to insemination with CoQ10 at a level of 10 $\mathrm{mg} / \mathrm{kg} \mathrm{LBE}$ or L-carnitine at level $40 \mathrm{mg} / \mathrm{kg} \mathrm{LBW}$ as daily oral dose is recommended to improve in vitro embryo production and also to increase litter characteristics (size and weight from birth up to weaning) of NEW Zealand White rabbit does.

\section{REFERENCES}

Abdelrazik, H. R.Sh; M.Reda and A. Ashok (2009). L-Carnitine decreases DNA damage and improves the in vitro blastocyst development rate in mouse embryos. Fertility and Sterility, 91(2):589-596.

Abdulhasan, M.A.K.; M.B.M.R. Fakhrildin and M.H. Shubber (2015). Effect of coq10 addition to maturation medium after vitrification of bovine oocytes. I.J.S.N., 6(1):40-44.

Ai, J.S.; Li, M.; H. Schatten and Q.Y. Sun (2009). Regulatory mechanism of spindle movements during oocyte meiotic division. Asian Aust J Anim Sci., 22:1447-1486.

Arrigoni-Martelli, E. and V. Caso (2001). Carnitine protects mitochondria and removes toxic acyls from xenobiotics. Drugs Exp. Clin. Res., 27:27-49. 
Baumgartner, M. and St. Jacobs (1999). L-carnitine: importance for pig breeding. Lohman Information, $22,15 \mathrm{pp}$.

Bentinger, M.; K. Brismar and G. Dallner (2007). The antioxidant role of coenzyme Q. Mitochondrion; (7Suppl):S41-50.

Bentov, Y.; N. Esfandiari; E. Burstein and R.F. Casper (2010). The use ofmitochondrial nutrients to improve the outcome of infertility treatment in older patients," Fertility and Sterility, 93(1):272-275.

Chankitisakul, V.; T. Somfai; Y. Inaba; M. Techakumphu and T. Nagai (2013). Supplementation of maturation medium with L-carnitine improves cryo-tolerance of bovine in vitro matured oocytes. Theriogenology, 79:590-598.

Cummins, J.M. (2004). The role of mitochondria in the establishment of oocyte functional competence. European Journal of Obstetrics, Gynecology, and Reproductive Biology, 115:S23-S29.

Doberenz, J.; C. Birkenfeld; H. Kluge and K. Eder (2005). The foetus receives more nutrients with Lcarnitine. International Pig Topics., 20(8):15-17.

Downs, S.M.; J.L. Mosey and J. Klinger (2009). Fatty acid oxidation and meiotic resumption mouse oocytes. Molecular Reproduction and Development, 76:844-853.

du Plessis, S.S.; K. Makker; N.R. Desai and A. Agarwal (2008). Impact of oxidative stress on IVF. Expet Rev Obstet Gynecol, 3:539-554.

Duncan, D.B. (1955). Multiple ranges and Multiple F-test. Biometrics, 11:1-42.

Dunning, K.R. and R.L. Robker (2012). Promoting lipid utilization with l-carnitine to improve oocyte quality. Anim Reprod Sci., 134(1-2):69-75.

Dunning, K.R.; L.K. Akison; D.L. Russell; R.J. Norman and R.L. Robker (2011). Increased $\beta$-oxidation and improved oocyte developmental competence in response to 1-carnitine during ovarian in vitro follicle development in mice. Biology of Reproduction, 85:548-555.

Dunning, K.R.; K. Cashman; D.L. Russell; J.G.Thompson and R.J,Norman (2010). Beta-oxidation is essential for mouse oocyte developmental competence and early embryo development. Biol Reprod., 83:909-918.

Eder, K. (2009). Influence of 1-carnitine on metabolism and performance of sows. Br J Nutr., 102:645654.

Eder, K.; A. Ramanau and H. Kluge (2003). Benefits of long term L-carnitine in sows. International Pig Topics., 18:25-26.

Eder, K.; A. Ramanau and H. Kluge (2001). Effect of L-carnitine supplementation on performance parameters in gilts and sows. J. Anim. Physiol. Anim. Nutr., 85:73- 80.

El-Shahat, K.H. and A.M. Abo-El Maaty (2010). The effect of dietary supplementation with calcium salts of long chain fatty acids and /or I-carnitine on ovarian activity of Rahmani ewes. Anim. Reprod. Sci., 117:78-82.

El-Tohamy, M.M.; M.S. Kotp; W.S. El-Nattat and A.H. Mohamed (2012). Semen Characteristics and Oxidative/Antioxidative Status in Semen and Serum of Male Rabbits Supplemented with Antioxidants during Heat Stress. Iranian Journal of Applied Animal Science, 2(2):175-183.

Ferguson, E.M. and H.J. Leese (2006). A potential role for triglyceride as an energy source during bovine oocyte maturation and early- embryo development. Mol Reprod Dev., 73:1195-1201.

Freemaut, G.; J. Roeymaecker, and J. Aerts (1993). Do lactating sows benefit from L-carnitine supplementation, Varkensbedrijf (June): 30.

Gosden, R. and B. Lee (2010). Portrait of an oocyte: Our obscure origin. J Clin Invest, 120:973-983.

Groff, J.L. and S.S. Gropper (2000). Advanced Nutrition and Human Metabolism. 3rd Edn., Wadsworth/Thomson Learning, Belmont, CA., USA.

Hashimoto, S. (2009). Application of in vitro maturation to assisted reproductive technology. J Reprod Dev., 55:1-10.

Hoppel, C. (2003). The role of carnitine in normal and altered fatty acid metabolism. Am. J. Kidney Dis., 41:S4-S12.

Iben, Ch. and J. Leibertseder (1994). Carnitine in Horse. Proceeding of the 4th Annual Congress of the European Society of Veterinary Internal Medicine (ESVIM), Brussels, (Belgium), and pp. 19.

Kalaiselvi, T. and C. Panneerselvam (1998). Effect of L-carnitine on the status of lipid peroxidation and antioxidants in aging J. Nutr. Biochem., 9: 575-581.

Kapoor, P. and A.K. Kapoor (2013). Coenzyme Q10 - A novel molecule. (Review article), JIACM, 14(1): 37-45.

Katayama, M.; Z.S. Zhong; L. Lai; P. Sutovsky; R.S. Prather and H. Schatten (2006). Mitochondria distribution and microtubule organization in fertilized and cloned porcine embryos: Implications for developmental potential. Dev Biol., 299:206-220.

Kerner, J. and C. Hoppel (2000). Fatty acid import into mitochondria. Biochim Biophys Acta, 1486:1-17. 
Kishi, T.; T. Okamoto; T. Takahashi; K. Goshimaand and T. Yamagami (1993). Cardiostimulatory action of coenzyme Q homologues on cultured myocardial cells and their biochemical mechanisms. Clin Invest., 71:S71-75.

Kruip, T.A.M.; D.G. Cran; T.H.V. Beneden and S.J. Dieleman (1983). Structural changes in bovine oocytes during final maturation in vitro. Gamete Res., 8:29-47.

Leibertsecler, J. and Ch. Iben (1994). Carnitine in poultry. Proceeding of the 4th annual congress of the European Society of Veterinary Internal Medicine' (ESVIM), Brussels, (Belgium) pp. 17.

Manzano, P.V.J.; B. Marlon; L.C. Ocampo; E.R.S. Ocampo and J.V.L. Maylem (2015). Improved Bovine Blastocyst Developmental Potential by L-carnitine Supplementation. International Journal of Scientific Research in Knowledge, 3(1):21-29.

Marriage, B.J.; M.T. Clandinin; I.M. Macdonald and D.M. Glerum (2004). Cofactor treatment improves ATP synthetic capacity in patients with oxidative phosphorylation disorders. Mol Genet Metab., 81(4):263-272.

McEvoy, T.; G. Coull; P. Broadbent; J. Hutchinson and B. Speake (2000). Fatty acid composition of lipids in immature cattle, pig and sheep oocytes with intact zona pellucida. J Reprod Fertil., 118:163170.

Mermillod, P.; R. Dalbiès-Tran; S. Uzbekova; A.Thélie; J.M. Traverso; C. Perreau; P. Papillier and P. Monget (2008). Factors affecting oocyte quality: who is driving the follicle?. Reprod. Domest. Anim., 43 Suppl 2:393-400.

Mirit Gendelman and Zvi Roth (2012). Incorporation of Coenzyme Q10 into Bovine Oocytes Improves Mitochondrial Features and Alleviates the Effects of Summer Thermal Stress on Developmental Competence. Biology of Reproduction, 87(5):11.

Miyamoto, K.; E.F. Sato; E. Kasahara; M. Jikumaru; K. Hiramoto; H. Tabata; M. Katsuragi; S. Odo; K. Utsumi and M. Inoue (2010). Effect of oxidative stress during repeated ovulation on the structure and functions of the ovary, oocytes, and their mitochondria.Free Radic Biol Med., 15; 49(4):674-81.

Musser, R.E.; R.D. Goodband ; M.D. Tokach; K.Q. Owen; J.L.Nelssen; S.A. Blum; S.S. Dritz and C.A. Civis (1999). Effects of L-Carnitine Fed During Gestation and Lactation on Sow and Litter Performance. J. Anim. Sci., 77:3289-3295.

Noseir, W.M.B. (2003). Ovarian follicular activity and hormonal profile during estrous cycle in cows: the development of 2 versus 3 waves Reproductive Biology and Endocrinology, 1:50.

Noseir, W.M.B. and G.A. El-Amrawi (2001). L-carnitine supplementation in normal and subfertile rams. Proc. 12th Ann. Cong. Egyptian Soc. Anim. Reprod. Fert., pp. 137.

Ravindranatha, B.M.; S. Nandi; P.S.P. Gupta and P.V. Sarma (2003). In vitro effects of different levels of commercially available PMSG on oocyte maturation. Buffalo J., 1:101-107.

Rizzo, A.M.; P. Berselli; S. Zava; G. Montorfano; M. Negroni and P. Corsetto (2010). Endogenous antioxidants and radical scavenger. Adv Exp Med Bio., 698:52-67.

SAS (1998). SAS/STAT®User's Guide: Statistics Ver. 6.04, 4th ed. SAS Institute Inc., Cary, NC., USA.

Schatten, H.; S. Qing-Yuan and P. Randall (2014). The impact of mitochondrial function/dysfunction on IVF and new treatment possibilities for infertility. Reproductive Biology and Endocrinology, 12:111.

Schatten, H. and Q.Y. Sun (2011b). Centrosome dynamics during meiotic spindle formation in oocyte maturation. Mol Reprod Devel, 78:757-768.

Schatten, H.; Q.Y. Sun (2011a). New insights into the role of centrosomes in mammalian fertilisation and implications for ART. Reproduction, 142:793-801.

Scott, Ch. (2013).The Role of Mitochondria from Mature Oocyte toViable Blastocyst. Obstetrics and Gynecology International, Article ID 183024, 10 pages. http://dx.doi.org/10.1155/2013/183024.

Sirard, M.A.; F. Richard; P. Blondin and C. Robert (2006). Contribution of the oocyte to embryo quality. Theriogenol, 65:126-136.

Smith, L.C.; J. Thundathil and F. Filion (2005). Role of the mitochondrial genome in preimplantation development and assisted reproductive technologies. Reproduction, Fertility, and Development, 17: 15-22.

Somfai, T.; M. Kaneda; S. Akagi; S. Watanabe and S. Haraguchi (2011). Enhancement of lipid metabolism with L-carnitine during in vitro maturation improves nuclear maturation and cleavage ability of follicular porcine oocytes. Reprod Fertil Dev., 23:912-920.

Stojkovic, M.; S.A. Machado; P. Stojkovic; V. Zakhartchenko; P. Hutzler; P.B. Goncalves and E. Wolf (2001). Mitochondrial distribution and adenosine triphosphate content of bovine oocytes before and after in vitro maturation: correlation with morphological criteria and developmental capacity after in vitro fertilization and culture. Biol Reprod., 64:904-909.

Stojkovic, M.; K. Westesen; V. Zakhartchenko; P. Stojkovic; K. Boxhammer, and E. Wolf (1999). Coenzyme Q (10) in submicron-sized dispersion improves development, hatching, cell proliferation, and adenosine triphosphate content of in vitro-produced bovine embryos. Biol Reprod; 61:541-547. 
Swain, J.E.and T.B. Pool (2008). ART failure: Oocyte contributions to unsuccessful fertilization. Hum Reprod Update, 14:431-446.

Takahashi, T.Y.I.; S. Tamas; K. Masahiro; G. Masaya; N. Takashi and M. Noboru (2013). Supplementation of culture medium with L-carnitine improves development and cryotolerance of bovine embryos produced in vitro. Reproduction, Fertility and Development, 25, 589-599.

Van Blerkom, J. (2011). Mitochondrial function in the human oocyte and embryo and their role in developmental competence. Mitochondrion; 11:797-813.

Vaz, F.M.; and R.J. Wanders (2002). Carnitine biosynthesis in mammals. Biochem. J., 361:417-429.

Ye, J.; J. Li; Y. Yu; Q. Wei; W. Deng and L. Yu (2010). L-Carnitine attenuates oxidant injury in HK-2 cells via ROS-mitochondria pathway. Regul. Pept., 161:58-66.

You, J.; J. Lee; S. Hyun and E. Lee (2012). L-carnitine treatment during oocyte maturation improves in vitro development of cloned pig embryos by influencing intracellular glutathione synthesis and embryonic gene expression. Theriogenology, 78:235-243.

Zhou, X.; F. Liu and S. Zhai (2007). Effect of L-carnitine and/or L-acetyl-carnitine in nutrition treatment for male infertility: a systematic review. Asia Pac J Clin Nutr., 16(Suppl 1):383-90.

\title{
حجم البطن والخصائص المبيضية والانضاج والاخصاب المعملى لبويضات امهات الارانب المعاملة با لكوانزيم كيو10والــ كارنيتين
}

\author{
جورج عزت يونان1 ، حمدى عبد الله النجار1، وائل محمد وفا1 ، ابراهيم طلعت الرطل1 و عبد الخالق السيد عبد الخالق2. \\ امعهج بحوث الانتاج الحيوانس - مركز البحوث الزراعية. الدقى- الجيزة - مصر. \\ هسم انتاج الحيوان-كلية الزراعة- جامعة المنصورة - مصر.
}

تهذف هذه الدر اسة الى تقييم تأثير الكو انزيم كيو 10 والــ كارنيتين على عدد الخلفات والخصائص المبيضية والانتاج المعملى لأجنة

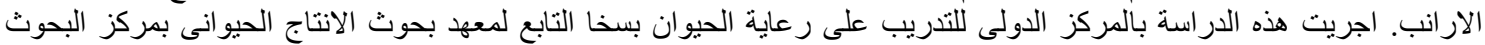

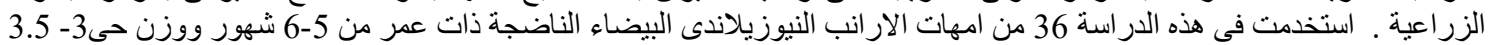

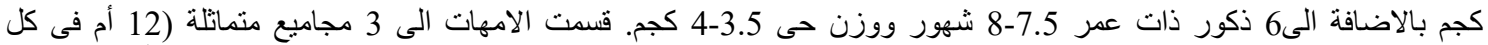

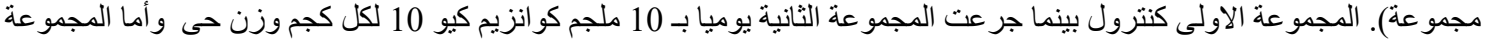

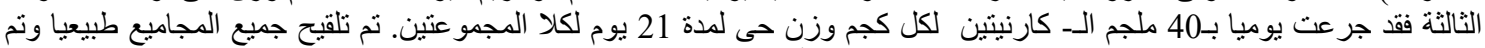

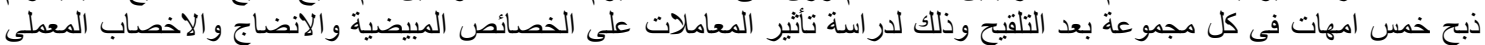

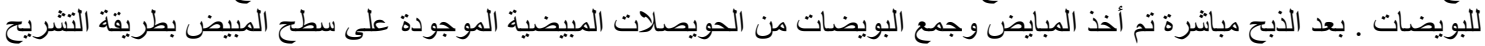

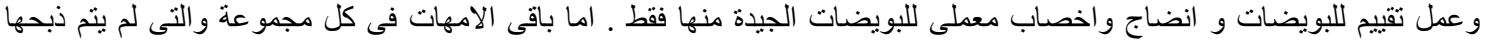

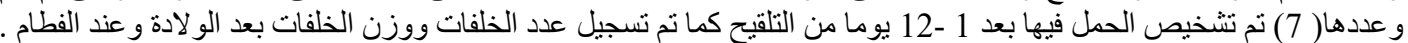

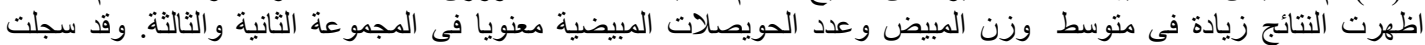

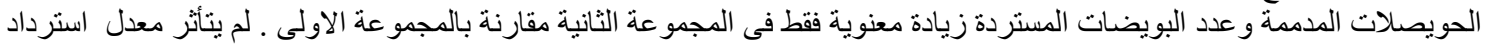

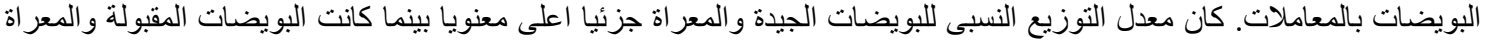

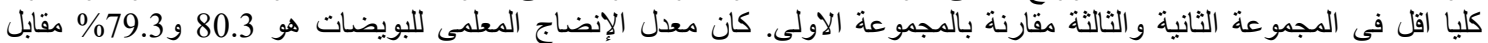

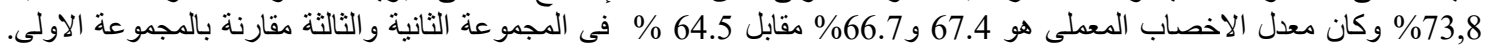

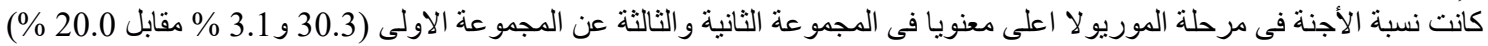

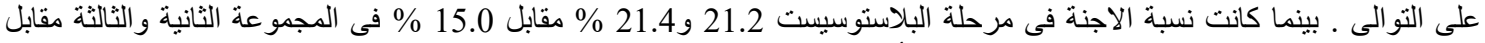

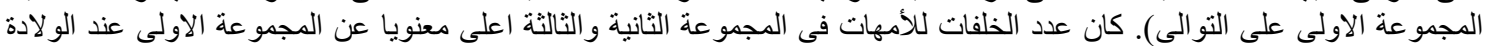

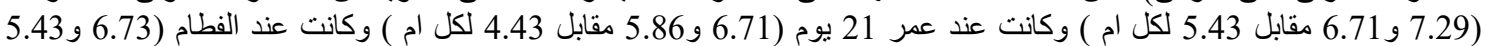

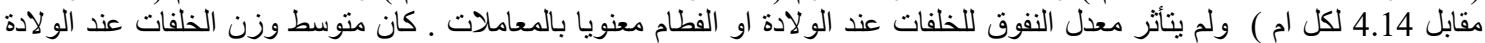

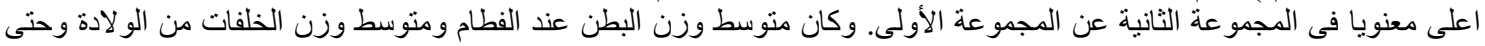

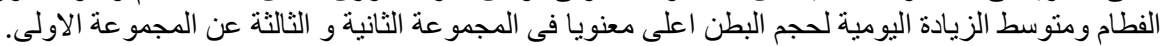

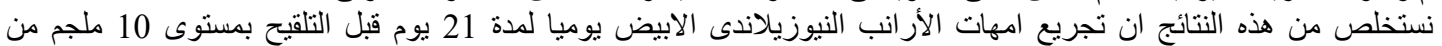

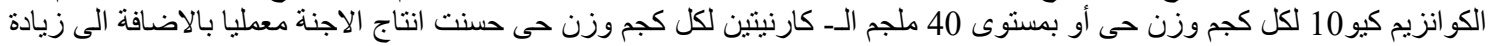
خصائص البطن (عدد ووزن الخلفات من الو لادة وحتى الفطام ) . 